Proceedings

\title{
Simulated Gastrointestinal Digestion Influences the In Vitro Hypolipidemic Properties of Coffee Pulp, a Potential Ingredient for the Prevention of Non-Alcoholic Fatty Liver Disease ${ }^{\dagger}$
}

\author{
Cheyenne Braojos 1,2,*, Miguel Rebollo-Hernanz ${ }^{1,2, *}$, Vanesa Benitez ${ }^{1,2}$, Silvia Cañas ${ }^{1,2}$, \\ Yolanda Aguilera ${ }^{1,2}$, Silvia M. Arribas ${ }^{3}$ and Maria A. Martin-Cabrejas ${ }^{1,2}$ \\ 1 Department of Agricultural Chemistry and Food Science, Universidad Autónoma de Madrid, 28049 \\ Madrid, Spain; vanesa.benitez@uam.es (V.B.); silvia.cannas@uam.es (S.C.); yolanda.aguilera@uam.es \\ (Y.A.); maria.martin@uam.es (M.A.M.-C.) \\ 2 Institute of Food Science Research, CIAL (UAM-CSIC), 28049 Madrid, Spain \\ 3 Department of Physiology, Universidad Autónoma de Madrid, 28029 Madrid, Spain; silvia.arribas@uam.es \\ * Correspondence: cheyenne.braojos@uam.es (C.B.); miguel.rebollo@uam.es (M.R.-H.) \\ + Presented at the The 1st International Electronic Conference on Nutrients - Nutritional and Microbiota \\ Effects on Chronic Disease, 02-15 November 2020; Available online: https://iecn2020.sciforum.net/.
}

Published: 30 October 2020

\begin{abstract}
Approximately $90 \%$ of the coffee cherry is discarded as waste during coffee bean processing. Coffee pulp has been validated as a potential safe ingredient and is a potential source of nutrients and health-promoting compounds that could be used as nutraceuticals to manage some chronic diseases. Metabolic disorders associated with dysregulated energy and cellular processes, such as obesity and hyperlipidemia, contribute to non-alcoholic fatty liver disease (NAFLD). In this sense, the main objective of this study was to evaluate the impact of an in vitro simulated digestion on the hypolipidemic properties of coffee pulp flour and the biological activity of the digested fractions of its flour and extract in HepG2 cells. The hypolipidemic properties of coffee pulp flour were tested by measuring the capacities of the residual fraction of each digestion to bind cholesterol and bile salts and to inhibit the lipase activity after simulated gastric, intestinal, and colonic in vitro digestion. The results exhibited that coffee pulp residual fraction had up to a 58\% $(p<0.05)$ more capacity to bind cholesterol, 1.9-fold $(p<0.05)$ higher bile salts binding capacity, and 1.5-fold ( $p<$ $0.05)$ higher ability to reduce the lipase activity than control residues. Likewise, the digested fractions of coffee pulp flour and extract $(50-250 \mu \mathrm{g} / \mathrm{mL})$ significantly $(p<0.05)$ alleviated the accumulation of fat $(14-35 \%)$, triglycerides $(5-27 \%)$, and cholesterol $(9-48 \%)$ triggered by the stimulation of HepG2 cells with palmitic acid $(500 \mu \mathrm{M})$ to simulate NAFLD. In conclusion, simulated gastrointestinal and colonic digestion improves coffee pulp hypolipidemic properties, enhancing its biological activity in cell culture models. Therefore, this coffee by-product could be an interesting potential ingredient to be used to prevent hyperlipidemia and regulate lipid metabolism.
\end{abstract}

Keywords: coffee pulp; coffee by-products; gastrointestinal digestion; hypolipidemic; hypocholesterolemic; non-alcoholic fatty liver disease

\section{Introduction}

The coffee beverage is one of the most consumed products worldwide, but approximately $90 \%$ of the coffee cherry is discarded as waste during coffee bean processing, which sometimes is not 
handled correctly and has a meaningful environmental impact [1,2]. These coffee by-products are also a potential source of compounds with functional properties, among other applications [1].

Coffee by-products comprise husks, skin and pulp, coffee mucilage, coffee parchment, coffee silverskin, and spent coffee grounds, but the composition depends on the type of processing employed: wet or dried $[3,4]$. Coffee pulp is one of the coffee by-products obtained during the wet processing of coffee beans. Coffee pulp composition is dietary fiber $(57 \%)$, carbohydrates $(20 \%)$, protein $(11 \%)$, and fat $(3 \%)$, and is an exciting source for animal feeding. However, its use is restricted due to the presence of non-nutritional factors $[4,5]$. On the other hand, the coffee pulp has been validated as a potential safe ingredient and is a potential source of nutrients and health-promoting compounds that could be used as nutraceuticals to manage some chronic diseases [6].

Non-alcoholic fatty liver (NAFLD) is the most frequent chronic liver disease worldwide, representing the hepatic manifestation of the metabolic syndrome which may develop from simple steatosis (i.e., fat accumulation in more than $5 \%$ of the hepatocytes) to necroinflammation and fibrosis, leading to non-alcoholic steatohepatitis (NASH), and in some instances to cirrhosis, liver failure and even to hepatocellular carcinoma [7,8]. Obesity and hyperlipidemia, among other diseases, predispose to NAFLD and may also contribute to the above-noted lipid disorders $[9,10]$. Nowadays, there is no established treatment for NAFLD; however, there are some practical recommendations on NAFLD management, supporting the diet's principal role [11].

Therefore, this study's main objective was to evaluate the impact of an in vitro simulated digestion on the hypolipidemic properties of coffee pulp flour and the biological activity of the digested fractions of its flour and extract in HepG2 cells.

\section{Materials and Methods}

\subsection{Materials}

Dulbecco's Modified Eagle Medium low glucose (1000 mg/mL) (DMEM) and 0.25\% trypsinEDTA were purchased from GE Healthcare Life Sciences. Fetal Bovine Serum (FBS), penicillinstreptomycin (100×) were obtained from Gibco Life Technologies. $o$-Phthalaldehyde, furfural, bile salts, lipase, Tween ${ }^{\circledR} 20$, Bovine Serum Albumin (BSA), Palmitic Acid (PA), 2',7'-Dichlorofluorescein diacetate (DCFDA), and Oil Red O were purchased from Sigma-Aldrich (St. Louis, MO, USA). All other chemicals and reagents were obtained from Panreac (Barcelona, Spain) unless otherwise specified.

\subsection{Coffee Flour and Aqueous Extracts Preparation}

Coffee pulp was provided by AORA Health (Spain). After milling, coffee pulp flour was obtained. Coffee aqueous extracts were obtained, as described by Rebollo-Hernanz et al. [12].

\subsection{INFOGEST Static In Vitro Simulation Digestion}

Digestions were carried out based on preliminary and optimized protocols described by Brodkorb et al. [13]

\subsection{Cholesterol Binding Capacity}

For the measure of the residue's cholesterol-binding capacity, fresh egg yolks were diluted 1:10 $(v / w)$, and the dilution was emulsified, divided, and adjusted to $\mathrm{pH} 2.0$ and $\mathrm{pH}$ 7.0. Samples $(0.1 \mathrm{~g})$ were mixed with the diluted egg yolk $(2 \mathrm{~mL})$ and incubated with agitation $\left(2 \mathrm{~h}, 37^{\circ} \mathrm{C}\right)$, followed by an $800 \times g$ centrifugation $(15 \mathrm{~min})$. Consecutively, samples supernatants $(0.1 \mathrm{~mL})$ were mixed with 0.6 $\mathrm{mL}$ of pure acetic acid, $0.2 \mathrm{~mL}$ of $\mathrm{H}_{2} \mathrm{SO}_{4}(96 \%)$, and $0.1 \mathrm{~mL}$ of $o$-Phthalaldehyde $(0.6 \mathrm{mg} / \mathrm{mL})$ and incubated while mixing for color development $\left(30 \mathrm{~min}, 60^{\circ} \mathrm{C}\right)$. Finally, triplicate measured absorbance at $550 \mathrm{~nm}$ using a microplate reader (Cytation 5, Biotek, Winooski, VT, USA). 


\subsection{Bile Salts Binding Capacity}

A mixture of $\mathrm{NaCl}(15 \mathrm{M}, \mathrm{pH} 7,0)$ and sodium cholate $(4.65 \mathrm{mM})$ was added to $0.1 \mathrm{~g}$ of the residual fraction of gastric and intestinal flour digestion. The samples were incubated for $3 \mathrm{~h}$ at $37^{\circ} \mathrm{C}$ while mixing, followed by an $800 \times g 15$ min centrifugation. Hereafter, $0.6 \mathrm{~mL}$ of $\mathrm{HCl}(45 \%)$ and 0.1 $\mathrm{mL}$ of furfural $(0.3 \%)$ were added to $0.1 \mathrm{~mL}$ of the supernatant. The samples were incubated with oscillations for color development $\left(30 \mathrm{~min}, 65^{\circ} \mathrm{C}\right)$. Absorbance was measured by triplicate at $620 \mathrm{~nm}$ using a microplate reader.

\subsection{Inhibitory Activity Against Pancreatic Lipase}

To determine the inhibitory activity against pancreatic lipase, a mixture consisting of olive oil (2 $\mathrm{mL})$, lipase ( $2 \mathrm{~mL}, 0.75 \mathrm{mg} / \mathrm{mL})$, bile salts $(5 \mathrm{~mL})$, and PBS 10X (5 mL, pH 7.2), was added to $0.1 \mathrm{~g}$ of the residual fraction of each flour digestion. Controls were carried with or without each compound (including residual fraction). Samples were incubated $\left(37^{\circ} \mathrm{C}, 1 \mathrm{~h}\right)$. The reaction was stopped in the cold for $5 \mathrm{~min}$, followed by centrifugation $(800 \times g, 15 \mathrm{~min})$. Hereafter, Tween ${ }^{\circledR} 20(0.2 \mathrm{~mL})$ was added to the supernatant of those samples that contained olive oil to emulsify the fats. Finally, each sample's lipase activity was measured using an acid-base titration with $\mathrm{NaOH}(0.02 \mathrm{M})$ and Phenolphthalein.

\subsection{Treatment Preparation for HepG2 Cells}

The digested fractions of coffee pulp flour (CPF) and extract (CPE) were diluted in DMEM free and filtered with $0.45 \mu \mathrm{m}$ cellulose acetate filters.

\subsection{Cell Culture Method}

HepG2 cells were obtained from ATCC, (Rockville, MD, USA). Cells were cultured in DMEM $\left(1000 \mathrm{~g} / \mathrm{mL}\right.$ glucose) supplemented with $10 \%$ FBS and $1 \%$ penicillin/streptomycin at $37{ }^{\circ} \mathrm{C}$ in a humidified atmosphere.

\subsubsection{Cell Viability}

HepG2 cells were seeded at $5 \times 10^{5}$ cells $/ \mathrm{mL}$ in 96 well culture plates and incubated for $24 \mathrm{~h}$. On day 2, cells were treated with CPF and CPE $(50-250 \mu \mathrm{g} / \mathrm{mL})$ for $24 \mathrm{~h}$ at $37{ }^{\circ} \mathrm{C}$ in a humidified atmosphere. On day 3, cell viability assay was performed with the CellTiter $96^{\circledR}$ AQueous MTS Reagent Powder (Promega Corporation, Madison, WI, USA) according to the manufacturer's instructions.

\subsubsection{NAFLD Induction in HepG2 Cells}

HepG2 were seeded at $1 \times 10^{5}$ cells $/ \mathrm{cm}^{2}$ in 96 well culture plates and incubated for $24 \mathrm{~h}$. On day 2, NAFLD was induced in HepG2 cells with PA $(500 \mu \mathrm{M})$, and they were treated with CPF or CPE $(100 \mu \mathrm{g} / \mathrm{mL})$ for $24 \mathrm{~h}$ at $37{ }^{\circ} \mathrm{C}$ in a humidified atmosphere. To prepare the PA solution, PA was conjugated with DMEM containing $1 \%$ BSA. Control cells were treated with $1 \%$ BSA only.

\subsubsection{Reactive Oxygen Species Formation in HepG2 Cells}

After $24 \mathrm{~h}$ incubation with treatments, NAFLD induction was determined by measuring the intracellular reactive oxygen species (ROS) formation by adding DCFDA $(25 \mu \mathrm{M})$. Fluorescence intensity was detected using a fluorescence microplate reader at an excitation/emission wavelength at $485 \mathrm{~nm} / 530 \mathrm{~nm}$, respectively. DCFDA was prepared according to the manufacturer's instructions.

\subsection{Biological Hypolipidemic Activity}

The accumulation of total lipids and intracellular triglycerides were performed as previously described by Rebollo-Hernanz et al. [12] using Oil Red O and a colorimetric triglycerides assay kit (Spinreact), respectively, according to manufacturer's instructions. Cholesterol accumulation was 
measured as previously described by Ryu et al. [14] using a colorimetric cholesterol assay kit (Spinreact) according to the manufacturer's instructions.

\subsection{Statistical Analysis}

All experiments were carried out by triplicate. Results are expressed as the mean \pm standard deviation (SD) $(n=3)$ and were assessed statistically by one-way analysis of variance (ANOVA) and post hoc Tukey test. Differences were defined as statistically significant for values of $p<0.05$. All analyses were performed using SPSS 24.0.

\section{Results}

\subsection{Simulated Gastrointestinal and Colonic Digestion Enhances the Hypolipidemic Properties of Coffee Pulp}

Digested residual fractions of coffee pulp flour had significantly more cholesterol and bile salts binding capcacity than control residues (Figure 1). Furthermore, the digested residue had higher bile salts binding capacity than the raw residue, which indicates that digestion enhanced this property. On the other hand, the digested residual fractions showed an increased binding cholesterol capacity as digestion went by, although it did not show a significant enhancement against raw residue. Gastric residual fraction had the lowest binding capacity for cholesterol; however, it had the highest binding capacity for bile salts. Moreover, the results exhibited that coffee pulp residual fraction had 1.5-fold $(p<0.05)$ higher ability to reduce the lipase activity than control residues.

\section{A}

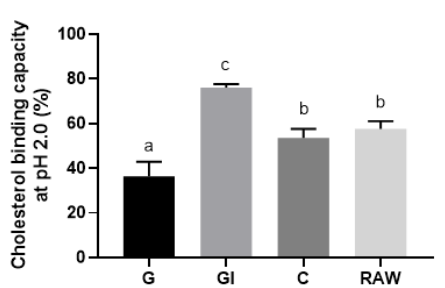

B

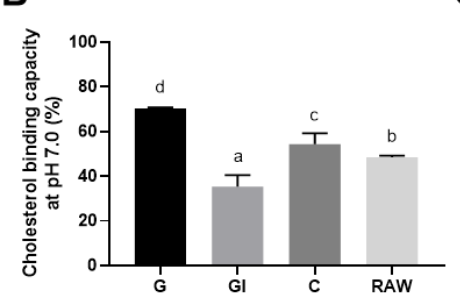

C

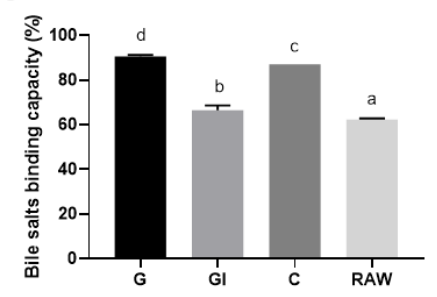

Figure 1. Hypolipidemic properties of coffee pulp digested residual fractions. (A) Cholesterol binding capacity of coffee pulp digested residual fractions at $\mathrm{pH} 2.0$; (B) Cholesterol binding capacity of coffee pulp digested residual fractions at $\mathrm{pH} 7.0$; (C) Bile salts binding capacity of coffee pulp digested residual fractions. The results are expressed as mean \pm SD. Bars with different letters significantly $(p$ $<0.05)$ differ according to ANOVA and Tukey's multiple range test. G: Gastric digestion residual fraction; GI: Intestinal residual fraction; C: Colonic residual fraction; RAW: Raw flour.

\subsection{Coffee pulp Is Not Toxic and Regulates ROS Production and the Accumulation of Lipids in Hepatocytes}

Cell cultures were incubated for $24 \mathrm{~h}$ with PA to simulate a model of NAFLD. MTS assay was used to determine the effect of different concentrations of CPE and CPF (50-250 $\mu \mathrm{g} / \mathrm{mL})$ on HepG2 proliferation, and the results showed that all the concentrations used were safe. ROS levels were measured to study the NAFLD induction. The results showed PA at a $500 \mu \mathrm{M}$ concentration increased significantly $(p<0.05)$ the ROS formation. Moreover, HepG2 cell morphology changed after incubation with PA, favoring to see lipid drops in some conditions (Figure 2).
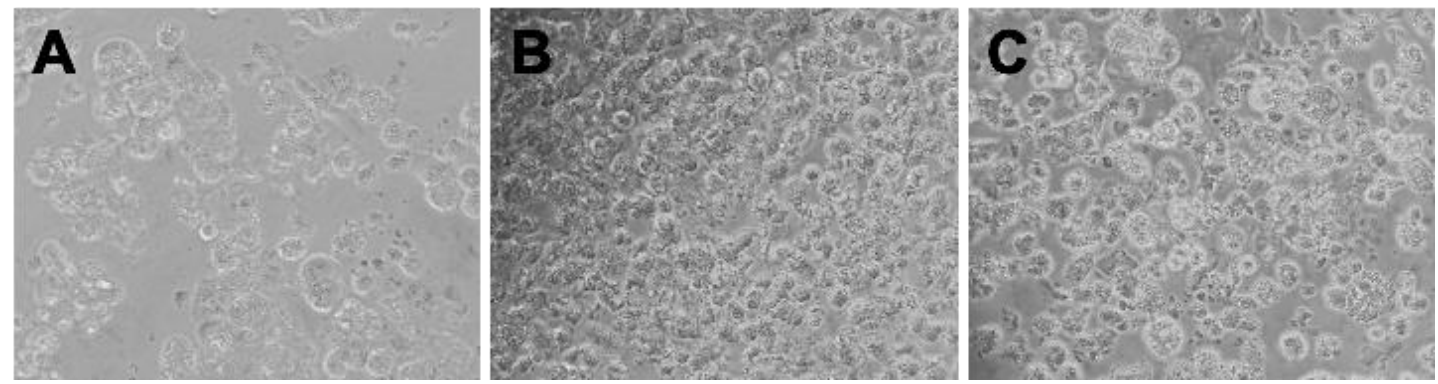
Figure 2. Illustrative representation of HepG2 morphologies after incubation in different conditions (A) Cells cultured in DMEM-BSA 1\%; (B) Cells cultured in DMEM-BSA 1\% with PA (500 $\mu \mathrm{M})$; (C) cells cultured in DMEM-BSA $1 \%$ with PA $(500 \mu \mathrm{M})$ with treatment (Intestinal CPE, $100 \mu \mathrm{g} / \mathrm{mL})$.

The results showed that CPF and CPE had a biological effect in HepG2 culture triggered by the cells' stimulation with PA $(500 \mu \mathrm{M})$. The digested fractions of CPF and CPE $(50-250 \mu \mathrm{g} / \mathrm{mL})$ significantly $(p<0.05)$ alleviated the accumulation of fat $(14-35 \%)$. Moreover, it also had an effect by modulating the triglycerides and cholesterol levels, lowering them about 5-27\% and 9-48\%, respectively.

\section{Discussion}

Dietary fiber (DF) is not absorbed nor digested during humans' gastrointestinal process, but it is wholly or partially fermented during intestinal digestion [15]. DF has a clear impact on lipid metabolism and cholesterol absorption [16,17]. The residual fraction of the simulated gastric digestion of coffee pulp showed lower cholesterol adsorption capacity at pH 2.0 than the intestinal residue at $\mathrm{pH}$ 7.0. Furthermore, colonic residual fraction showed the highest cholesterol-binding capacity at both pHs. These results suggest that cholesterol-binding capacity improves during digestion phases. DF properties may also change during the digestion process, explaining why cholesterol-binding capacity improves during the digestion phase. Previous studies have already demonstrated that DF's presence reduces bile salts' reabsorption by binding them [18]. The residual fraction of the simulated gastric and colonic digestion of coffee pulp showed higher bile salts binding capacity than raw material. During the digestion process, DF is supposed to play an essential role in the bile salts binding process because DF inhibits its surfactant activity during intestinal digestion, which reduces micelles formations and consequently might reduce circulating triglycerides [19]. $\mathrm{pH}$ changes during the digestion process might explain it. Either way, this hypolipidemic property could be important to prevent and reduce the accumulation of circulating triglycerides in NAFLD context, among other diseases. The residual fraction of the simulated gastrointestinal digestion of coffee pulp also showed more inhibitory activity against pancreatic lipase. Previous studies have suggested that DF and phenolic compounds present on it might inhibit pancreatic lipase [20].

These studies suggest that coffee pulp digestion could enhance its hypolipidemic properties, which could have an important role in the treatment or prevention of NAFLD, among other chronic diseases. In this regard, studies in HepG2 cells showed that CPE and CPF reduced lipid, cholesterol, and triglycerides accumulation after the induction of simulated NAFLD, which might be used to treat this disease. The mechanism underlying the progression of NAFLD was not elucidated. However, some authors have suggested that oxidative stress and mitochondrial dysfunction could be critical factors [21]. Previous studies have shown that coffee extract could have antioxidant effects on HepG2 cell lines [22]. Evaluating the effects of digestion on coffee pulp antioxidant properties could also be necessary, and the results showed that CPE and CPF could exert a significant role as nutraceuticals. From this perspective and relying on these results, researching the effect of digestion on hypolipidemic properties and the biological activity of coffee pulp, among other coffee by-products, is vital to revalorize them as novel ingredients, which will also have a positive impact on the environment. Further investigations on the digested fractions of the digested coffee pulp and their in vivo functional properties will be completed to confirm coffee pulp's health properties.

\section{Conclusions}

In conclusion, simulated gastrointestinal and colonic digestion improves the hypolipidemic properties of coffee pulp, enhancing its biological activity in cell culture models. Therefore, this coffee by-product could be an interesting potential ingredient to prevent hyperlipidemia and regulate lipid metabolism.

Author Contributions: Conceptualization, M.R.-H., V.B., Y.A. and M.A.M.-C; methodology, M.R.-H., S.C. and Y.A.; formal analysis, C.B. and M.R.-H.; investigation, C.B.; data curation, C.B. and S.C.; writing-original draft preparation, C.B. and M.R.-H.; writing-review and editing, C.B., M.R.-H., and V.B.; visualization, M.R.H.; 
supervision, V.B. and M.A.M.-C.; funding acquisition, S.M.A. and M.A.M.-C. All authors have read and agreed to the published version of the manuscript.

Funding: This research was funded by the COCARDIOLAC project from the Spanish Ministry of Science and Innovation (RTI 2018-097504-B-I00).

Conflicts of Interest: The authors declare no conflict of interest.

\section{References}

1. Esquivel, P.; Jiménez, V.M. Functional properties of coffee and coffee by-products. Food Res. Int. 2012, 46, 488-495, doi:10.1016/j.foodres.2011.05.028.

2. Iriondo-Dehond, A.; Iriondo-Dehond, M.; Del Castillo, M.D. Applications of compounds from coffee processing by-products. Biomolecules 2020, 10, 1-20, doi:10.3390/biom10091219.

3. Mussatto, S.I.; Machado, E.M.S.; Martins, S.; Teixeira, J.A. Production, Composition, and Application of Coffee and Its Industrial Residues. Food Bioprocess Technol. 2011, 4, 661-672, doi:10.1007/s11947-011-0565-z.

4. Ulloa Rojas, J.B.; Verreth, J.A.J.; Amato, S.; Huisman, E.A. Biological treatments affect the chemical composition of coffee pulp. Bioresour. Technol. 2003, 89, 267-274, doi:10.1016/S0960-8524(03)00070-1.

5. Moreno, J.; Cozzano, S.; Mercedes Pérez, A.; Arcia, P.; Curutchet, A. Coffee Pulp Waste as a Functional Ingredient: Effect on Salty Cookies Quality. J. Food Nutr. Res. 2019, 7, 632-638, doi:10.12691/jfnr-7-9-2.

6. Iriondo-DeHond, A.; Aparicio García, N.; Fernandez-Gomez, B.; Guisantes-Batan, E.; Velázquez Escobar, F.; Blanch, G.P.; San Andres, M.I.; Sanchez-Fortun, S.; del Castillo, M.D. Validation of coffee by-products as novel food ingredients. Innov. Food Sci. Emerg. Technol. 2019, 51, 194-204, doi:10.1016/j.ifset.2018.06.010.

7. Demir, M.; Lang, S.; Steffen, H.M. Nonalcoholic fatty liver disease-Current status and future directions. J. Dig. Dis. 2015, 16, 541-557, doi:10.1111/1751-2980.12291.

8. Matteoni, C.A.; Younossi, Z.M.; Gramlich, T.; Boparai, N.; Yao Chang Liu; McCullough, A.J. Nonalcoholic fatty liver disease: A spectrum of clinical and pathological severity. Gastroenterology 1999, 116, 1413-1419, doi:10.1016/S0016-5085(99)70506-8.

9. Milić, S.; Lulić, D.; Štimac, D. Non-alcoholic fatty liver disease and obesity: Biochemical, metabolic and clinical presentations. World J. Gastroenterol. 2014, 20, 9330-9337, doi:10.3748/wjg.v20.i28.9330.

10. Gaggini, M.; Morelli, M.; Buzzigoli, E.; DeFronzo, R.A.; Bugianesi, E.; Gastaldelli, A. Non-alcoholic fatty liver disease (NAFLD) and its connection with insulin resistance, dyslipidemia, atherosclerosis and coronary heart disease. Nutrients 2013, 5, 1544-1560, doi:10.3390/nu5051544.

11. Vilar-Gomez, E.; Martinez-Perez, Y.; Calzadilla-Bertot, L.; Torres-Gonzalez, A.; Gra-Oramas, B.; GonzalezFabian, L.; Friedman, S.L.; Diago, M.; Romero-Gomez, M. Weight loss through lifestyle modification significantly reduces features of nonalcoholic steatohepatitis. Gastroenterology 2015, 149, 367-378.e5, doi:10.1053/j.gastro.2015.04.005.

12. Rebollo-Hernanz, M.; Zhang, Q.; Aguilera, Y.; Martín-Cabrejas, M.A.; Gonzalez de Mejia, E. Phenolic compounds from coffee by-products modulate adipogenesis-related inflammation, mitochondrial dysfunction, and insulin resistance in adipocytes, via insulin/PI3K/AKT signaling pathways. Food Chem. Toxicol. 2019, 132, 110672, doi:10.1016/j.fct.2019.110672.

13. Brodkorb, A.; Egger, L.; Alminger, M.; Alvito, P.; Assunção, R.; Ballance, S.; Bohn, T.; Bourlieu-Lacanal, C.; Boutrou, R.; Carrière, F.; et al. INFOGEST static in vitro simulation of gastrointestinal food digestion. Nat. Protoc. 2019, 14, 991-1014, doi:10.1038/s41596-018-0119-1.

14. Ryu, H.M.; Kim, Y.J.; Oh, E.J.; Oh, S.H.; Choi, J.Y.; Cho, J.H.; Kim, C.D.; Park, S.H.; Kim, Y.L. Hypoxanthine induces cholesterol accumulation and incites atherosclerosis in apolipoprotein E-deficient mice and cells. J. Cell. Mol. Med. 2016, 20, 2160-2172, doi:10.1111/jcmm.12916.

15. Macagnan, F.T.; da Silva, L.P.; Hecktheuer, L.H. Dietary fibre: The scientific search for an ideal definition and methodology of analysis, and its physiological importance as a carrier of bioactive compounds. Food Res. Int. 2016, 85, 144-154, doi:10.1016/j.foodres.2016.04.032.

16. Hong, Y.; Zi-jun, W.; Jian, X.; Ying-jie, D.; Fang, M. Development of the dietary fiber functional food and studies on its toxicological and physiologic properties. Food Chem. Toxicol. 2012, 50, 3367-3374, doi:10.1016/j.fct.2012.05.011.

17. Benitez, V.; Rebollo-Hernanz, M.; Hernanz, S.; Chantres, S.; Aguilera, Y.; Martin-Cabrejas, M.A. Coffee parchment as a new dietary fiber ingredient: Functional and physiological characterization. Food Res. Int. 2019, 122, 105-113, doi:10.1016/j.foodres.2019.04.002. 
18. Story, J.A.; Kritchevsky, D. 胆汁酸（Bile Acid） | 用語集 | 腸内細菌学会, 2018.

19. Capuano, E. The behavior of dietary fiber in the gastrointestinal tract determines its physiological effect. Crit. Rev. Food Sci. Nutr. 2017, 57, 3543-3564, doi:10.1080/10408398.2016.1180501.

20. Grundy, M.M.L.; Edwards, C.H.; Mackie, A.R.; Gidley, M.J.; Butterworth, P.J.; Ellis, P.R. Re-evaluation of the mechanisms of dietary fibre and implications for macronutrient bioaccessibility, digestion and postprandial metabolism. Br. J. Nutr. 2016, 116, 816-833, doi:10.1017/S0007114516002610.

21. Fontes, A.; Alemany-Pagès, M.; Oliveira, P.J.; Ramalho-Santos, J.; Zischka, H.; Azul, A.M. Antioxidant versus pro-apoptotic effects of mushroom-enriched diets on mitochondria in liver disease. Int. J. Mol. Sci. 2019, 20, 3987, doi:10.3390/ijms20163987.

22. Baeza, G.; Amigo-Benavent, M.; Sarriá, B.; Goya, L.; Mateos, R.; Bravo, L. Green coffee hydroxycinnamic acids but not caffeine protect human HepG2 cells against oxidative stress. Food Res. Int. 2014, 62, 1038-1046, doi:10.1016/j.foodres.2014.05.035.

Publisher's Note: MDPI stays neutral with regard to jurisdictional claims in published maps and institutional affiliations.

(C) 2020 by the authors. Submitted for possible open access publication under the terms and conditions of the Creative Commons Attribution (CC BY) license (http://creativecommons.org/licenses/by/4.0/). 